\title{
AUDITORIA ARQUIVÍSTICA: uma proposta de requisitos
}

\author{
ARCHIVAL AUDIT: \\ a proposal of basic requirements
}

Danielle Alves Batista ${ }^{1}$

Eliane Braga Oliveira²

\begin{abstract}
RESUMO
Estudo sobre auditoria arquivística onde discutem-se os conceitos de auditoria, arquivística e gestão de documentos. Discorre sobre a gestão de documentos na administração pública com ênfase na informação orgânica e no patrimônio público documental, bem como sobre a fiscalização da gestão de arquivos públicos com 0 objetivo de propor requisitos básicos para a realização de auditoria arquivística. As técnicas para coleta de dados são a pesquisa bibliográfica e a pesquisa documental. Realiza uma análise comparativa entre os requisitos identificados na literatura de auditoria, relaciona-os com a Legislação Arquivística Brasileira e as recomendações de três autores da disciplina arquivística: Antonia Heredia Herrera, Heloisa Liberalli Belotto e Theodore R. Schellenberg. Os resultados são uma proposta de requisitos básicos para a auditoria arquivística e a identificação das contribuições da auditoria às funções arquivísticas. Concluiu-se que a auditoria arquivística pode contribuir para o aprimoramento da gestão pública e da formação do patrimônio cultural brasileiro.
\end{abstract}

Palavras-chave: Auditoria. Auditoria Arquivística. Auditoria de Gestão de Documentos.

\begin{abstract}
Study about archival audit through the discussion of the concepts of audit, archival and records management. It discusses the records management in public administration with emphasis on the organic information and public documentary heritage Debates about the examination of the public archives management. The data collection techniques were bibliographic research and documentary research. It performs a comparative analysis between the requirements identified in the audit literature, relates them to the Brazilian Archival Laws and the recommendations of three recognized authors of the archival discipline: Antonia Heredia Herrera, Heloisa Liberalli Belotto and Theodore R. Schellenberg. The results are a proposal of basic requirements for the archival audit and the identification of the contributions of the audit to the archival functions. The paper concludes that the archival audit could contribute to the improvement of public management and to the brazilian cultural heritage constitution.

Keywords: Audit. Archival audit. Records management audit.
\end{abstract}

Artigo recebido em 16/01/2019 e aceito para publicação em 24/02/2019

1 Mestre em Ciência da Informação pela Universidade de Brasília, Brasil. Doutoranda da University of British Columbia - School of Library, Archival and Information Studies, Canadá. Arquivista do Ministério Público do Distrito Federal e Territórios, Brasil. E-mail: danilusasm@gmail.com.

2 Doutora em Ciência da Informação, pela Universidade de Brasília., Brasil. Professora do curso de graduação em Arquivologia e do Programa de Pós-Graduação da Universidade de Brasília, Brasil. E-mail: elianebo@unb.br. 


\section{INTRODUÇÃO}

A gestão de documentos é uma atividade administrativa, de caráter estratégico, tendo em vista a sua potencial contribuição para a tomada de decisão. A Lei 8.158, de 08 de janeiro de 1991, estabelece em seu Art. 10: "É dever do Poder Público a gestão documental e a proteção especial a documentos de arquivos, como instrumento de apoio à administração, à cultura, ao desenvolvimento científico e como elementos de prova e informação" (BRASIL, 1991).

Além disso, um dos produtos da gestão documental é a constituição dos arquivos permanentes que, no caso dos documentos públicos, conforme previsto na Constituição Federal de 1988, são considerados patrimônio cultural brasileiro.

0 processo de auditoria constitui-se em uma atividade de controle fundamental para os procedimentos de qualquer tipo de gestão e proporciona transparência e confiabilidade às instituições que a utilizam.

0 Brasil possui políticas públicas de arquivo, apresenta uma legislação arquivística satisfatória e que caminha em convergência com as demandas atuais. No entanto, o que se observa é que não há um procedimento específico para o controle do tratamento dispensado aos documentos de arquivos das instituições públicas. A legislação pode ser satisfatória, mas sem fiscalização, seu cumprimento fica comprometido.

Este trabalho busca compreender a atividade de auditoria arquivística por meio da comparacao entre os conceitos de auditoria, auditoria de gestão de documentos, auditora arquivística e as abordagens metodológicas propostas nesta última área. Analisa também duas iniciativas vigentes voltadas para a auditoria operacional e a auditoria arquivística.

Há escassa literatura acerca da temática aqui apresentada, especialmente no que tange às experiências brasileiras. Apesar da lacuna teórica em torno da temática, há uma crescente necessidade de análise e retroalimentação dos processos de trabalho relacionados à prática arquivística, especialmente após a Lei $n^{0}$ 12.527, de 18 de novembro de 2011, cujas determinações só poderão ser atendidas caso as instituições possuam uma efetiva política de gestão documental e arquivos.

Diante da falta de literatura e das crescentes demandas sociais acerca da transparência, faz-se necessário um estudo mais aprofundado sobre a atividade de auditoria arquivística que nos possibilite responder: quais os requisitos imprescindíveis ao desenvolvimento de tal atividade? Quais os critérios a serem analisados por um auditor de atividades arquivísticas? É por meio do levantamento da literatura 
arquivística, da legislação arquivística brasileira e da literatura sobre os diversos tipos de auditoria que esta pesquisa busca responder tais questionamentos.

A atividade de fiscalizar as práticas arquivísticas faz-se importante tanto para garantir a adoção de boas práticas no tratamento dos documentos públicos, quanto para a preservação do patrimônio

público arquivístico. É uma atividade que também possibilita a avaliação dos serviços dos arquivos públicos e a qualificação das instituições avaliadas.

A presente pesquisa possui características exploratórias, tendo em vista 0 fato de a prática de auditoria em arquivos ser desconhecida no âmbito da disciplina arquivística brasileira. A abordagem metodológica deste estudo é qualitativa, pois sua ênfase está em compreender a auditoria arquivística enqunto conceito e apontar formas mais eficientes para sua execução. As técnicas usadas para coleta de dados foram a pesquisa bibliográfica e a pesquisa documental.

Os dados foram analisados a partir dos requisitos de auditoria identificados na literatura, as diretrizes apontadas pela legislação e parte da literatura da disciplina arquivística. Os resultados alcançados foram uma proposta de requisitos mínimos para a auditoria arquivística e a contribuição desta atividade para as funções arquivísticas.

\section{A AUDITORIA}

\subsection{Evolução e conceito}

A auditoria surgiu pela necessidade de "confirmação dos registros contábeis, em virtude do aparecimento das grandes empresas e da taxação de imposto de renda" (FRANCO; MARRA, 2001, p. 39). Alguns autores identificam o início dessa atividade na Inglaterra, no século XIV, que auditava contas públicas desde 1314. A prática sistematizada, porém, se deu somente no século XIX (FRANC0; MARRA, 2001, p. 39).

Inicialmente, as auditorias concentravam-se na "verificação dos registros contábeis, que visavam à comprovação de que eles eram exatos” (HERNANDES JÚNIOR, 1995, p. 11). A finalidade primordial das primeiras auditorias era "detectar desfalques e verificar se os indivíduos que ocupavam cargos de confiança agiam honestamente, prestavam contas de seus atos" (COOK; WINKLE, 1983, p. 13).

Sua evolução ocorreu junto ao desenvolvimento econômico, com o surgimento das grandes empresas de capital aberto, cuja confirmação dos registros contábeis passou a ser exigência para atrair 
investidores. Ocorreu, portanto, como "consequência de crescimento das empresas, do aumento de sua complexidade e do envolvimento do interesse da economia popular nos grandes empreendimentos" (FRANCO; MARRA, 2001, p. 39).

Pela necessidade de verificar e fiscalizar os registros das grandes empresas de capital aberto nasceu a auditoria externa ou auditoria independente, com o intuito de permitir que potenciais investidores conhecessem "a posição patrimonial e financeira, a capacidade de gerar lucros e como estava sendo efetuada a administração financeira dos recursos", certificando-se assim da sua segurança, liquidez e rentabilidade (ALMEIDA, 1996, p. 21). A exigência para este tipo de análise passou a ser que fossem "examinadas por um profissional independente da empresa e de reconhecida capacidade técnica" (ALMEIDA, 1996, p. 21 e 22).

A auditoria é uma forma de controle. Para Ferreira, auditoria "pode significar verificação administrativa, fiscalização financeira, ou ainda o poder de ter sob seu domínio o comando e a fiscalização" (FERREIRA, 1982, p. 34).

Conforme Peter e Machado,

[...] analisando mais especificamente a função controle, pode-se observar que esta era vista como uma simples verificação, a posteriori, se tudo havia ocorrido de acordo com 0 planejado. Essa verificação necessitava de informações apresentadas em forma de relatório sobre o desempenho das diversas áreas da organização, cuja grande fonte fornecedora era a Contabilidade (PETER; MACHADO, 2003, p. 21).

0 conceito de auditoria não é unânime, tendo em vista sua modificação através do tempo e do espaço. Seu desenvolvimento acompanha as modificações e evoluções nos contextos organizacionais e a amplitude cada vez maior dos trabalhos de auditoria. Inicialmente seu foco eram as falhas e erros e atinha-se às ações passadas. Atualmente, seu escopo é voltado para a análise de ações do passado e do presente, vislumbrando melhorias para o futuro.

A norma ABNT NBR ISO n 19011:2012 define auditoria como o "processo sistemático, documentado e independente para obter evidências de auditoria e avaliá-las objetivamente para determinar a extensão na qual os critérios da auditoria são atendidos”. (ASSOCIAÇÃO BRASILEIRA DE NORMAS TÉCNICAS, 2012, p. 1).

Cook e Winkle a definem como "o estudo e avaliação sistemáticos de transações, procedimentos, operações e das demonstrações financeiras resultantes. Sua finalidade é determinar o grau de observância dos critérios estabelecidos e emitir um parecer sobre o assunto" (COOK; WINKLE, 1983, p. 4). 
A auditoria também é definida como um "controle de controles" e explicada como "uma atividade de avaliação [...] independente dentro de uma organização" (BACON, 1973, p. 41).

Guedes e Araújo Júnior a definem como "a atividade permanente, metódica e sistemática de verificação dos procedimentos, dos registros, das práticas de gestão e dos resultados de uma organização". Apontam a sua finalidade como a verificação das disposições planejadas, sua implementação com eficácia, sua conformidade com normas e objetivos, e se estes foram atingidos (GUEDES; ARAÚJO JÚNIOR, 2014, p. 34).

0 Tribunal de Contas da União (TCU) sintetizou vários dos conceitos de auditoria chegando ao que denominou "conceito geral de auditoria", onde afirma que "auditoria é o processo sistemático, documentado e independente de se avaliar objetivamente uma situação ou condição para determinar a extensão na qual critérios são atendidos, obter evidências quanto a esse atendimento e relatar os resultados dessa avaliação a um destinatário predeterminado" (TRIBUNAL DE CONTAS DA UNIÃO, 2011, p. 4).

Conforme o TCU (2011, p. 14), as auditorias classificam-se em auditoria de regularidade e auditoria operacional. A classificação das auditorias depende do objetivo principal de cada trabalho, tendo em vista serem componentes do todo da auditoria governamental.

A auditoria de regularidade consiste em "examinar a legalidade e a legitimidade dos atos de gestão dos responsáveis sujeitos à jurisdição do Tribunal, quanto aos aspectos contábil, financeiro, orçamentário e patrimonial”. É composta pelas auditorias de conformidade e as contábeis.

A auditoria operacional objetiva "examinar a economicidade, eficiência, eficácia e efetividade de organizações, programas e atividades governamentais, coma finalidade de avaliar seu desempenho e de promover o aperfeiçoamento da gestão pública."

Já o Manual do Sistema de Controle Interno do Poder Executivo Federal, da Controladoria-Geral da União (CGU), classifica as auditorias em: auditoria de avaliação de gestão; auditoria de acompanhamento de gestão; auditoria contábil; auditoria operacional e auditoria especial (CONTROLADORIA-GERAL DA UNIÃO, 2001, P. 33).

A auditoria de avaliação de gestão busca emitir posicionamento sobre a regularidade das contas, verifica a execução de contratos, acordos, convênios ou ajustes, probidade na aplicação de recursos, cumprimento da legislação pertinente e avalia os resultados quanto à economicidade, eficiência e eficácia.

A auditoria de acompanhamento de gestão é realizada ao longo dos processos de gestão. Ocorre em tempo real e objetiva evidenciar melhorias e economias durante o processo, ou prevenir gargalos ao desempenho da missão institucional. 
Auditoria contábil diz respeito ao controle do patrimônio de uma unidade, entidade ou projeto, com o objetivo de obter elementos suficientes que comprovem a regularidade das operações contábeis e da situação econômico-financeira do avaliado.

A auditoria operacional

[...] consiste em avaliar as ações gerenciais e os procedimentos relacionados ao processo operacional, ou parte dele, das unidades ou entidades da administração pública federal, programas de governo, projetos, atividades, ou segmentos destes, com a finalidade de emitir uma opinião sobre a gestão quanto aos aspectos da eficiência, eficácia e economicidade, procurando auxiliar a administração na gerência e nos resultados, por meio de recomendações, que visem aprimorar os procedimentos, melhorar os controles e aumentar a responsabilidade gerencial. (CONTROLADORIA-GERAL DA UNIÃO, 2001, p. 33)

Conforme assinala Albuquerque,

Diferentemente das auditorias tradicionais, nas quais os procedimentos e rotinas são perfeitamente definidos e os auditores executam, muitas vezes, programas-padrão, nas auditorias operacionais o planejamento é dinâmico, flexível e contínuo, estendendo-se por todo 0 curso dos trabalhos. (ALBUQUERQUE, 2007, p. 76)

A auditoria é um processo onde são identificadas várias funções e atividades, executadas em determinado período com produção de resultados. As finalidades principais de todos esses processos de controle podem resumir-se em duas: combater o abuso de poder e transmitir à sociedade segurança e confiança nas ações do Estado, garantindo transparência e participação popular na gestão pública.

Conforme os objetivos estabelecidos neste trabalho, é possível afirmar que, apesar das grandes discussões acerca da definição de auditoria, esta prática mantém relação com qualquer atividade administrativa que envolva processos de trabalho, como é o caso tanto da gestão de documentos quanto da arquivística.

\subsection{Conceitos relacionados ao estudo da auditoria arquivística}

0 conceito de auditoria está totalmente relacionado às funções de controle, daí a importância em discutir as origens do termo controle, suas definições, bem como as diferenças entre controle interno e controle externo.

Conforme Castro, "o vocábulo controle tem sentido amplo, podendo significar dominação (hierarquia/subordinação), direção (comando), limitação (proibição), vigilância (fiscalização contínua), verificação (exame), registro (identificação)" (CASTRO, 2013, p. 34). 0 mesmo autor afirma que 0 termo sempre esteva associado às finanças. 
Diferenciando o controle interno do externo, temos o conceito de Bacon, que define controle interno como "o conjunto de normas mediante as quais se realiza a administração dentro de uma organização, e a qualquer dos numerosos recursos para supervisionar e dirigir uma operação determinada, ou as operações em geral" (BACON, 1973, p. 41). Para Medauar (2012, p. 49), "mais adequado seria dizer que o controle interno da Administração Pública é a fiscalização que a mesma exerce sobre os atos e atividades de seus órgãos e das entidades descentralizadas que lhe são vinculadas".

Dentre as Normas Brasileiras de Contabilidade (NBC), a norma NBC T 16.8 define controle interno, sob o enfoque contábil, como:

[...] o conjunto de recursos, métodos, procedimentos e processos adotados pela entidade do setor público com a finalidade de:

(a) salvaguardar os ativos e assegurar a veracidade dos componentes patrimoniais;

(b) dar conformidade ao registro contábil em relação ao ato correspondente;

(c) propiciar a obtenção de informação oportuna e adequada;

(d) estimular adesão às normas e às diretrizes fixadas;

(e) contribuir para a promoção da eficiência operacional da entidade;

(f) auxiliar na prevenção de práticas ineficientes e antieconômicas, erros, fraudes, malversação, abusos, desvios e outras inadequações (CONSELHO FEDERAL DE CONTABILIDADE, 2008, p. 1).

0 controle externo é uma atividade que, no Brasil, realiza-se predominantemente por meio de “auditorias e inspeções de natureza contábil, financeira, orçamentária, operacional e patrimonial”, seguindo normas técnicas e diretrizes de padrão internacional (TRIBUNAL DE CONTAS DA UNIÃO, 2011, p. 23).

Um dos objetivos deste trabalho é identificar diferenças conceituais entre auditoria de gestão de documentos e auditoria arquivística. Para o alcance deste objetivo, é necessário discutir as definições desses dois termos, de forma a apontar suas especificidades.

Para Heredia Herrera, gestão documental:

É uma expressão que aceitamos e incorporamos ao nosso vocabulário [...] a partir da tradução francesa do records management anglo-saxão que é relacionado à teoria das três idades. Expressão e conceito que [...] não correspondia com nossa realidade arquivística, tanto quanto o records management supunha uma atenção só aos documentos administrativos pelos gestores documentais sem contar com a existência dos Arquivos e à margem dos arquivistas (HEREDIA HERRERA, 2013, p. 72).

A definição de gestão de documentos proposta no Dicionário de Terminologia Arquivística é: "conjunto de medidas e rotinas visando à racionalização e eficiência na criação, tramitação, classificação, uso primário e avaliação de arquivos" (CAMARGO; BELLOTTO, 1996, p. 41). 
Conforme a Lei $n^{0} 8.159$, gestão de documentos é "o conjunto de procedimentos e operações técnicas referentes à sua produção, tramitação, uso, avaliação e arquivamento em fase corrente e intermediária, visando a sua eliminação ou recolhimento para guarda permanente". Trata-se da mesma definição utilizada pelo Dicionário Brasileiro de Terminologia Arquivística do Arquivo Nacional (2005), que a equipara ao termo "administração de documentos".

A norma ISO 30300:2011 define gestão de documentos da seguinte forma:

[...] área de gestão responsável por um controle eficaz e sistemático da criação, recepção, manutenção, uso e ordenação dos documentos, incluindo os processos para incorporar e manter, em forma de documentos, a informação e prova das atividades e operações da organização (INTERNATIONAL ORGANIZATION OF STANDARDIZATION, 2011, p. 11, tradução nossa).

Schellenberg (2004) conclui que a gestão documental "preocupa-se, assim, com todo o período de vida da maioria dos documentos". Assim sendo, "exerce um controle parcial sobre o uso corrente dos documentos e ajuda a determinar os que devem ser destinados ao "inferno" do incinerador, ao "céu" de um arquivo permanente, ou ao "limbo" de um depósito intermediário" (SCHELLENBERG, 2004, p. 68).

A arquivística é algo maior, mais abrangente que a gestão de documentos, daí a relevância desta revisão de conceitos para a diferenciação das duas auditorias.

0 Dicionário Brasileiro de Terminologia Arquivística do Arquivo Nacional considera que os conceitos de arquivística e arquivologia são os mesmos, definindo-a como "disciplina que estuda as funções do arquivo e os princípios e técnicas a serem observados na produção, organização, guarda, preservação e utilização dos arquivos. Também chamada arquivística.” (ARQUIVO NACIONAL, 2005, p. 37).

Rousseau e Couture definem arquivística como a "disciplina que rege a gestão da informação orgânica (arquivos)", podendo assumir três formas:

Uma forma unicamente administrativa (records management), cuja principal preocupação é ter em conta o valor primário do documento; uma forma tradicional que põe a tónica unicamente no valor secundário do documento; uma forma nova, integrada e englobante, que tem como objectivo ocupar-se simultaneamente do valor primário e do valor secundário do documento (ROUSSEAU; COUTURE, 1998, p. 284).

Finalmente, Herrera considera que as linhas mestras da arquivística atual são:

1) 0 objeto da Arquivística segue sendo duplo: os documentos de arquivo, em papel e eletrônicos, e todos os Arquivos, como instituições, sempre que sejam tais, [...]

5) Há uma atenção preferente aos documentos antes que aos Arquivos, aqui o protagonismo da gestão documental. [...] uma gestão documental que suponha uma continuidade desde a produção dos documentos até depois de decidida sua conservação permanente. 
6) Os contextos, junto com os atributos e as relações desempenham um papel muito importante na hora da identificação ou reconhecimento dos documentos. A localização e a recuperação são devedores dos três.

7) Existe um protagonismo das funções e dos processos que se faz patente na hora da classificação, da avaliação, da descrição, da gestão de qualidade (HEREDIA HERRERA, 2013, p. 27-28).

Observa-se que a gestão ou administração de documentos volta-se para o documento enquanto produto da atividade administrativa. Sua ênfase está no valor primário do documento de arquivo, e seu tratamento relaciona-se com as noções administrativas de eficiência, eficácia, efetividade e economicidade.

Por outro lado, a arquivística preocupa-se, além do valor primário documental, com os arquivos enquanto instituições e com outros valores dissociados das veias administrativas, como o social e 0 cultural.

A relação das práticas de auditoria e controle com a gestão documental e a arquivística são evidentes. A atividade de auditar surgiu da busca de conformidade entre registros. Sua relação com a contabilidade e com a administração se dá desde os seus primórdios. A gestão documental é um macro processo integrante do rol das atividades administrativas, portanto pode perfeitamente ser controlada por meio de auditoria e fiscalização.

A arquivística extrapola as fronteiras da gestão documental. Trata também de diretrizes teóricas para realização das atividades de arquivo, tanto no âmbito das organizações administrativas, quanto no âmbito das instituições arquivísticas. 0 grau de observância dessas diretrizes pode ser entendido como objeto de uma auditoria arquivística.

Para efeitos desta pesquisa consideraremos auditoria conforme o conceito formulado pelo TCU "o processo sistemático, documentado e independente de se avaliar objetivamente uma situação ou condição para determinar a extensão na qual critérios são atendidos, obter evidências quanto a esse atendimento e relatar os resultados dessa avaliação a um destinatário predeterminado" (TRIBUNAL DE CONTAS DA UNIÃO, 2011, p. 4).

0 conceito formulado pelo TCU foi considerado o ideal para conduzir este estudo por reforçar características fundamentais do processo de controle: processo sistemático (padronizado e regulamentado); documentado e com evidências, por ser necessariamente baseado em registros de informação que comprovem suas constatações; independente e avaliação objetiva como garantia de imparcialidade nos relatos e observações; atendimento de critérios, já que a conformidade é requisito 
do controle; relato de resultados, pois o relatório ou parecer serão obrigatoriamente o produto final do processo de auditoria.

Quanto à classificação das auditorias optou-se por utilizar a proposta da CGU, por ser uma proposta voltada para a realidade da gestão pública brasileira.

A referência de controle interno deste trabalho é a proposta do CFC:

[...] o conjunto de recursos, métodos, procedimentos e processos adotados pela entidade do setor público com a finalidade de: salvaguardar os ativos e assegurar a veracidade dos componentes patrimoniais; dar conformidade ao registro contábil em relação ao ato correspondente; propiciar a obtenção de informação oportuna e adequada; estimular adesão às normas e às diretrizes fixadas; contribuir para a promoção da eficiência operacional da entidade; auxiliar na prevenção de práticas ineficientes e antieconômicas, erros, fraudes, malversação, abusos, desvios e outras inadequações (CONSELHO FEDERAL DE CONTABILIDADE, 2008, p. 33)

A definição de arquivística que mais se adequa a esta pesquisa é a de Rousseau e Couture, em sua terceira hipótese, descrevendo a arquivística como a "disciplina que rege a gestão da informação orgânica (arquivos)", como "uma forma nova, integrada e englobante, que tem como objectivo ocupar-se simultaneamente do valor primário e do valor secundário do documento" (ROUSSEAU; COUTURE, 1998, p. 284).

Além desta definição considerou-se também a relevância da visão de Heredia Herrera de que "0 objeto da arquivística segue sendo duplo: os documentos de arquivo, em papel e eletrônico, e todos os Arquivos como instituições, [...]”. (HEREDIA HERRERA, 2013, p. 27).

Conclui-se que a auditoria arquivística estudada nesta pesquisa inclui-se nas auditorias operacionais, por serem estas mais voltadas para a análise, tanto na questão da conformidade (com leis, decretos, regulamentos) quanto na questão da melhoria dos processos de trabalho.

\section{A LEGISLAÇÃO ARQUIVÍSTICA BRASILEIRA}

Compreender a política de arquivos no Brasil é parte do processo de entendimento da atividade de auditoria arquivística proposta neste trabalho.

Questões diretamente relacionadas aos arquivos estão presentes na Constituição Federal de 1988. 0 inciso XXXIII do art. $5^{\circ}$ explicita 0 direito de acesso às informações públicas, direito posteriormente regulamentado pela Lei $n^{0}$ 12.527, de 18/11/2011. Além disso, 0 artigo 216 inclui os documentos entre os bens constituintes do patrimônio cultural brasileiro.

A legislação referente ao tema não se limita à Carta Magna, e este trabalho busca ressaltar que, apesar de contemplar muitos dos aspectos voltados para a gestão de documentos e para o tratamento 
dos arquivos permanentes, a falta de fiscalização, no âmbito das instituições, do cumprimento das determinações legais é um dos fatores que compromete o cumprimento da legislação arquivística em vigor.

Dentre as leis federais de maior relevância merecem destaque: a Lei $n^{0} 5.433$, de 8 de maio de 1968, "regula a microfilmagem de documentos oficiais e dá outras providências"; a Lei n 5.869 , de 11 de janeiro de 1973, que institui o Código de Processo Civil e reforça o valor de prova dos documentos de arquivo; a Lei n 8.159 , de 8 de janeiro de 1991, mais conhecida como Lei de Arquivos, que "dispõe sobre a política nacional de arquivos públicos e privados e dá outras providências"; e a Lei n 12.527 , de 18 de novembro de 2011, conhecida como Lei de Acesso à Informação (LAI) que conferiu aos documentos de arquivo maior visibilidade e importância.

Os decretos relacionados a algumas dessas leis são: Decreto $n^{0} 82.590$, de 06 de novembro de 1978; Decreto $n^{0} 4.073$, de 3 de janeiro de 2002 e Decreto $n^{0} 7.724$, de 16 de maio de 2012.

0 Conselho Nacional de Arquivos (CONARQ), que conforme a Lei nº 8.159 é o órgão responsável pela formulação da política nacional de arquivos, instituiu 43 resoluções, que regulamentam desde a necessidade de adoção de instrumentos arquivisticos pelos órgãos da administração pública, até a análise da qualidade do papel reciclado para a produção e manutenção de documentos de arquivo.

0 Sistema Nacional de Arquivos (SINAR), possui como finalidade "implementar a política nacional de arquivos públicos e privados, visando à gestão, à preservação e ao acesso aos documento de arquivo" (BRASIL, 2002). Seu órgão central é o CONARQ e seus demais integrantes são: o Arquivo Nacional; os arquivos do Poder Executivo Federal; os arquivos do Poder Legislativo Federal; os arquivos do Poder Judiciário Federal; os arquivos estaduais dos Poderes Executivo, Legislativo e Judiciário; 0 arquivo do Distrito Federal dos Poderes Executivo, Legislativo e Judiciário; os arquivos municipais dos Poderes Executivo e Legislativo.

0 mesmo decreto expressa as atribuições do órgão central a as competências dos integrantes do SINAR. Esse dispositivo ainda aborda os documentos públicos, a gestão de documentos da administração pública federal e da declaração de interesse público e social de arquivos privados.

0 sistema e a política nacionais de arquivo no Brasil são importantes para a estruturação dos requisitos propostos com base na legislação arquivística brasileira. 


\section{REQUISITOS DE AUDITORIA}

Apresentam-se, aqui, os modelos de auditoria que contribuíram para a formulação da questão motivadora deste trabalho: 0 Manual de Auditoria Operacional do TCU e 0 Guía para la auditoría archivística, do Archivo General de La Nación, do México.

A auditoria arquivística, conforme abordado no referencial teórico, está contextualizada dentre as auditorias operacionais. A auditoria operacional, no ponto de vista de Araújo, consiste em "revisões metódicas de programas, organizações, atividades ou segmentos operacionais dos setores público e privado, com a finalidade de avaliar e comunicar se os recursos da organização estão sendo usados eficientemente e se estão sendo alcançados os objetivos operacionais" (ARAÚJ0, 2004, p. 23).

Não há uma metodologia estabelecida, nem um conjunto de práticas determinadas como escopo da auditoria operacional, Albuquerque afirma que "pelo contrário, se está diante de um conjunto de práticas, teorias e discursos em desenvolvimento e ainda pouco definidos" (ALBUQUERQUE, 2007, p. 45).

\subsection{Manual de Auditoria Operacional do TCU}

Um dos modelos utilizado como parâmetro para a elaboração dos requisitos de uma auditoria arquivística é o Manual de Auditoria Operacional do TCU, cujo objetivo é "definir princípios e padrões que orientem a realização e o controle de qualidade das auditorias operacionais a cargo das unidades técnicas do Tribunal" (TRIBUNAL DE CONTAS DA UNIÃO, 2010, p. 9).

A proposta do tribunal consiste em um ciclo contínuo composto das seguintes etapas: seleção; planejamento; execução; relatório; comentário do gestor; apreciação; divulgação e monitoramento.

A primeira etapa, da seleção, trata da seleção do objeto de auditoria e é o início do ciclo. Conforme o manual, esta etapa é importante para a "definição de um objeto que ofereça oportunidade para a realização de auditoria que contribua para o aperfeiçoamento da administração pública e forneça à sociedade opinião independente sobre o desempenho da atividade pública" (TRIBUNAL DE CONTAS DA UNIÃO, 2010, p. 15). Nesta fase serão apontados todos os objetos de auditoria com base em critérios preestabelecidos, integradamente com o planejamento estratégico, e também por meio de levantamento de dados.

0 planejamento é constituído pelas seguintes atividades: análise preliminar do objeto de auditoria; definição do objetivo e escopo da auditoria; especificação dos critérios de auditoria; elaboração da 
matriz de planejamento; validação da matriz de planejamento; elaboração de instrumentos de coleta de dados; teste piloto; e elaboração do projeto de auditoria.

Durante a fase de execução, as principais atividades são: desenvolvimento dos trabalhos de campo; análise dos dados coletados; elaboração da matriz de achados de auditoria3; validação da matriz de achados de auditoria.

0 relatório é o "principal produto da auditoria" (TRIBUNAL DE CONTAS DA UNIÃO, 2010, p. 43). Nele verificam-se os objetivos da auditora, suas questões, metodologia, achados, conclusões e a proposta de encaminhamento, conforme o Manual de Auditoria Operacional do TCU. 0 Manual apresenta várias especificações e padrões internacionais para a apresentação deste documento.

Finalmente o monitoramento é a "verificação do cumprimento das deliberações do TCU e dos resultados delas advindos, com o objetivo de verificar as providências adotadas e aferir seus efeitos". Este procedimento aumenta a probabilidade de solução dos problemas detectados durante uma auditoria (TRIBUNAL DE CONTAS DA UNIÃO, 2010, p. 53).

\subsection{Guía para la auditoria archivística}

0 Archivo General de La Nación, do México, lançou em julho de 2015 o Guía para la auditoria archivística, que afirma ser esta atividade "uma estratégia para incentivar o cumprimento normativo e dos processos técnico da gestão documental na Administração Pública Federal” (ARCHIVO GENERAL DE LA NACIÓN, 2015, p. 5).

Os objetivos do material são: servir de ferramenta de trabalho para os órgãos internos de controle emitindo para eles as recomendações necessárias; avaliar o cumprimento normativo e os processos técnicos arquivísticos para garantir a integridade, acessibilidade e conservação dos documentos através de sistemas modernos de gestão documental; e avaliar as atividades desempenhadas no sistema institucional de arquivos, aprimorando continuamente os serviços arquivísticos e a gestão documental (ARCHIVO GENERAL DE LA NACIÓN, 2015, p. 5). Seu âmbito de aplicação é toda e qualquer instituição da administração pública federal e sua metodologia se dá por meio de entrevista in loco, inspeção física e revisão de documentos e registros.

3 Achado de auditoria é "a discrepância entre a situação existente e o critério. Achados são situações verificadas pelo auditor durante 0 trabalho de campo que serão usadas para responder às questões de auditoria" (TCU, 2010). 
0 guia foi elaborado com base nas melhores práticas e padrões internacionais e avalia três níveis da gestão documental: a) nível estrutural - verifica o estabelecimento de um sistema de arquivos institucional, recursos humanos, financeiros e materiais para seu adequado funcionamento, regula os processos técnicos com os que operam os diferentes tipos de arquivo da instituição, o perfil de cada responsável e as condições físicas de conservação dos documentos de arquivo; b) nível documental - comprova a elaboração e atualização dos instrumentos de controle e consulta arquivística; c) nível normativo - verifica o cumprimento das disposições provenientes da legislação federal do México.

0 guia é dividido em dois instrumentos: um questionário de diagnóstico para a auditoria arquivística e cinco questionários denominados "cédula analítica de verificação do cumprimento de obrigações em matéria de arquivos" para uso e avaliação a ser feita pelos órgãos de controle interno do país.

0 questionário de diagnóstico visa identificar, de forma geral, a situação arquivística das instituições auditadas.

Nesse modelo, os requisitos para avaliação da situação arquivística são: elaboração de diagnóstico inicial; execução da avaliação por um órgão interno de controle; análise do cumprimento da legislação; avaliação da aplicação de boas práticas com os documentos de arquivo em todas as suas idades; elaboração de recomendações.

Foi possível observar que o material proposto pelo TCU foi elaborado de forma a nortear a proposição de auditorias operacionais e contribui com os macro requisitos de uma auditoria arquivística. 0 modelo elaborado pelo Archivo General de La Nación, do México, fornece procedimentos mais especificos acerca da atividade de auditoria arquivística.

\subsection{Proposta de requisitos para a auditoria arquivística}

Propor requisitos mínimos de auditoria arquivística tornará o processo de fiscalização confiável.

Antes da proposição dos requisitos, componente da etapa de levantamento de dados, faz-se necessário apontar quais das etapas sugeridas pelo Manual de Auditoria Operacional do TCU, anteriores a esta, serão essenciais ao processo de auditoria arquivística.

A primeira etapa é o planejamento, pois será necessário determinar todo o escopo da auditoria, apontando objetivos, justificativa e resultados pretendidos. A segunda etapa é a execução, que consiste na proposta de requisitos deste trabalho, onde a análise dos dados levantados será o subsídio para a 
elaboração da terceira etapa: confecção do relatório ou parecer de auditoria. A quarta etapa consiste na divulgação do relatório, que servirá como feedback para a unidade auditada.

É importante frisar que realizar o monitoramento periódico das unidades auditadas é um procedimento que garante a implantação das recomendações e melhorias descritas no relatório, bem como o constante acompanhamento da evolução da efetividade dos serviços de arquivo das instituições.

A proposta de requisitos baseada na legislação arquivística brasileira e nas melhores práticas foi sistematizada em um quadro, contendo os dispositivos legais ou teóricos que justificam cada um dos itens a serem verificados durante a auditoria arquivística, bem como o índice de relevância de cada requisito, podendo ser obrigatório, recomendável e opcional. A relevância foi atribuída conforme as determinações legais e teóricas da arquivística.

Os requisitos também foram classificados dentre as principais funções arquivísticas, com 0 intuito de facilitar a compreensão da contribuição desta pesquisa da seguinte forma: 1) política de gestão de arquivos; 2) produção e registro; 3) avaliação; 4) classificação e arranjo; 5) descrição; 6) acesso; 7) difusão/ comunicação; e 8) preservação e conservação.

Quadro 1 - Requisitos para a auditoria arquivística

\begin{tabular}{|c|c|c|c|}
\hline $\mathrm{N}^{\mathrm{o}}$ & Requisito & Dispositivo legal/ teórico & Relevância \\
\hline 1 & \multicolumn{3}{|c|}{ POLÍTICA DE GESTÃ̃O DOS ARQUIVOS } \\
\hline 1.1 & $\begin{array}{l}\text { Política de gestão de arquivos na } \\
\text { instituição que inclua, além de documentos } \\
\text { convencionais, os documentos digitais, } \\
\text { audiovisuais, iconográficos, sonoros e } \\
\text { musicais }\end{array}$ & $\begin{array}{l}\text { Lei } n^{0} 8.159 \\
\text { Resolução CONARQ nº } \\
41 \text {, art. } 1^{\circ}\end{array}$ & Obrigatório \\
\hline 1.2 & $\begin{array}{l}\text { Política de preservação de documentos, } \\
\text { incluindo documentos especiais }\end{array}$ & $\begin{array}{l}\text { Resolução CONARQ n } \\
41 \text {, art. } 1^{\circ}\end{array}$ & Obrigatório \\
\hline 1.3 & $\begin{array}{l}\text { Planejamento anual das ações relacionadas } \\
\text { à gestão dos arquivos }\end{array}$ & $\begin{array}{l}\text { SCHELLENBERG, 2004, } \\
\text { p. } 172\end{array}$ & Obrigatório \\
\hline 1.4 & $\begin{array}{l}\text { Serviço de assistência técnica da instituição } \\
\text { arquivística de sua esfera. }\end{array}$ & Lei $\mathrm{n}^{0} 8.159$, art. 17 & Recomendável \\
\hline 1.5 & $\begin{array}{l}\text { Plano de disseminação das normas } \\
\text { relacionadas ao tratamento dos arquivos }\end{array}$ & $\begin{array}{l}\text { Decreto } n^{0} 4.073, \text { art. } 13, \\
\text { inciso II }\end{array}$ & Obrigatório \\
\hline .6 & $\begin{array}{l}\text { Plano de racionalização das atividades } \\
\text { arquivísticas }\end{array}$ & $\begin{array}{l}\text { Decreto } \mathrm{n}^{0} 4.073, \text { art. 13, } \\
\text { inciso III }\end{array}$ & Recomendável \\
\hline 1.7 & $\begin{array}{l}\text { Ações de manutenção do Cadastro Nacional } \\
\text { de Entidades Custodiadoras }\end{array}$ & $\begin{array}{l}\text { Decreto } \mathrm{n}^{0} 4.073 \text {, art. 13, } \\
\text { inciso XI } \\
\text { Resolução CONARQ } n^{0} \\
28, \text { art. } 4^{0}\end{array}$ & Obrigatório \\
\hline
\end{tabular}




\begin{tabular}{|c|c|c|c|}
\hline 1.8 & $\begin{array}{l}\text { Ações de estímulo à participação de } \\
\text { servidores/ funcionários/ empregados em } \\
\text { câmaras técnicas, setoriais ou comissões } \\
\text { especiais do CONARQ }\end{array}$ & $\begin{array}{l}\text { Decreto } n^{0} 4.073, \text { art. 13, } \\
\text { inciso XII }\end{array}$ & Opcional \\
\hline 1.9 & $\begin{array}{l}\text { Determinação de procedimentos de } \\
\text { avaliação da qualidade dos serviços de } \\
\text { arquivo }\end{array}$ & HERRERA, 2013, p. 129 & Recomendável \\
\hline 2 & \multicolumn{3}{|c|}{ PRODUÇÃO E REGISTRO } \\
\hline 2.1 & $\begin{array}{l}\text { Conjunto de procedimentos de } \\
\text { racionalização da produção documental }\end{array}$ & HERRERA, 2013, p. 111 & Recomendável \\
\hline 2.2 & $\begin{array}{l}\text { Disponibilidade de sistemas eletrônicos } \\
\text { de gestão arquivística de documentos } \\
\text { informação para registro dos documentos }\end{array}$ & $\begin{array}{l}\text { Resolução CONARQ } n^{0} \\
20 \text {, art. } 3^{\circ}\end{array}$ & Obrigatório \\
\hline 2.3 & $\begin{array}{l}\text { Controle de numeração de protocolo dos } \\
\text { documentos da instituição. }\end{array}$ & $\begin{array}{l}\text { SCHELLENBERG, 2004, } \\
\text { p. } 98\end{array}$ & Obrigatório \\
\hline 2.4 & $\begin{array}{l}\text { Utilização dos requisitos estabelecidos pelo } \\
\text { e-ARQ Brasil para construção dos sistemas }\end{array}$ & $\begin{array}{l}\text { Resolução CONARQ } n^{0} \\
\text { 20, art. } 3^{0}, \S 4^{0} \\
\text { Resolução CONARQ } n^{0} 25\end{array}$ & Obrigatório \\
\hline 2.5 & $\begin{array}{l}\text { Ações de estímulo à participação de } \\
\text { arquivistas e instituições arquivísticas } \\
\text { públicas na construção dos sistemas }\end{array}$ & $\begin{array}{l}\text { Resolução CONARQ no } \\
20 \text {, art. } 3^{\circ}\end{array}$ & Recomendável \\
\hline 3 & \multicolumn{3}{|c|}{ AVALIAÇÃO } \\
\hline 3.1 & Plano de destinação de documentos & $\begin{array}{l}\text { SCHELLENBERG, 2004, } \\
\text { p. } 135\end{array}$ & Obrigatório \\
\hline 3.2 & $\begin{array}{l}\text { Realização das atividades de avaliação } \\
\text { exclusivamente pela instituição }\end{array}$ & $\begin{array}{l}\text { Resolução CONARQ n }{ }^{0} 6, \\
\text { art. } 1^{\circ}\end{array}$ & Obrigatório \\
\hline 3.3 & $\begin{array}{l}\text { Realização de eliminação de documentos } \\
\text { desprovidos de valor }\end{array}$ & Lei $n^{0} 8.159$, art. $9^{\circ}$ & Obrigatório \\
\hline 3.4 & $\begin{array}{l}\text { Descarte de cópias dos documentos cujos } \\
\text { originais encontram-se na instituição }\end{array}$ & HERRERA, 2013, p. 109 & Recomendável \\
\hline 3.5 & $\begin{array}{l}\text { Eliminação de documentos apenas com } \\
\text { autorização da instituição arquivística na } \\
\text { esfera de competência }\end{array}$ & $\begin{array}{l}\text { Lei } n^{0} 8.159 \text {, de } \\
\text { 08/01/1991, art. 90 } \\
\text { Resolução CONARQ } n^{0} 40\end{array}$ & Obrigatório \\
\hline 3.6 & $\begin{array}{l}\text { Ações para a publicação de editais de } \\
\text { eliminação em Diário Oficial ou em outro } \\
\text { veiculo caso não existam os veículos oficiais }\end{array}$ & $\begin{array}{l}\text { Resolução CONARQ n } n^{0} \text {, } \\
\text { art. } 1^{\circ}\end{array}$ & Obrigatório \\
\hline 3.7 & $\begin{array}{l}\text { Elaboração da listagem de eliminação } \\
\text { seguindo as recomendações do CONARQ }\end{array}$ & $\begin{array}{l}\text { Resolução CONARQ no } \\
40 \text {, art. } 3^{\circ}\end{array}$ & Obrigatório \\
\hline 3.8 & $\begin{array}{l}\text { Elaboração da listagem de eliminação } \\
\text { de documentos com especial ênfase ao } \\
\text { conteúdo dos documentos }\end{array}$ & $\begin{array}{l}\text { SCHELLENBERG, 2004, } \\
\text { p. } 143\end{array}$ & Recomendável \\
\hline 3.9 & $\begin{array}{l}\text { Publicação de Termos de Eliminação de } \\
\text { documentos em periódicos oficiais ou, } \\
\text { na ausência destes, jornais de grande } \\
\text { circulação }\end{array}$ & $\begin{array}{l}\text { Resolução CONARQ } n^{0} \\
40 \text {, art. } 4^{\circ}\end{array}$ & Obrigatório \\
\hline
\end{tabular}




\begin{tabular}{|c|c|c|c|}
\hline 3.10 & $\begin{array}{l}\text { Atividades de seleção por amostragem } \\
\text { dos documentos cuja destinação final é } \\
\text { eliminação }\end{array}$ & HERRERA, 2013, p. 122 & Recomendável \\
\hline 3.11 & $\begin{array}{l}\text { Estabelecimento de regras que garantam } \\
\text { o respeito ao prazo de } 30 \text { a } 45 \text { dias para } \\
\text { manifestações após a publicação de edital de } \\
\text { eliminação }\end{array}$ & $\begin{array}{l}\text { Resolução CONARQ nº } 5 \\
\text { art. } 2^{\circ}\end{array}$ & Obrigatório \\
\hline 3.12 & $\begin{array}{l}\text { Comissão Permanente de Avaliação de } \\
\text { Documentos }\end{array}$ & $\begin{array}{l}\text { Decreto } \mathrm{n}^{0} 4.073, \text { de } \\
03 / 01 / 2002 \text {, art. } 18\end{array}$ & Obrigatório \\
\hline 3.13 & $\begin{array}{l}\text { Instrumentos de avaliação de documentos } \\
\text { da atividade-meio aprovados ou uso da } \\
\text { Resolução } \mathrm{n}^{0} 14 \text {, do CONARQ, e instrumentos } \\
\text { de avaliação de documentos da atividade-fim } \\
\text { aprovados pela instituição arquivística da } \\
\text { específica esfera de competência }\end{array}$ & $\begin{array}{l}\text { Decreto } \mathrm{n}^{\circ} 4.073, \text { art. } 18, \\
\S 1^{\circ} \\
\text { Resolução CONARQ } \mathrm{n}^{\circ} \\
14, \text { art. }^{\circ}\end{array}$ & Obrigatório \\
\hline 3.14 & $\begin{array}{l}\text { Plano para a destruição total física dos } \\
\text { documentos cuja eliminação foi autorizada }\end{array}$ & $\begin{array}{l}\text { SCHELLENBERG, 2004, } \\
\text { p. } 143\end{array}$ & Recomendável \\
\hline 3.15 & $\begin{array}{l}\text { Estabelecimento de ações de recolhimento } \\
\text { de documentos de guarda permanente para } \\
\text { instituição arquivística da específica esfera }\end{array}$ & Decreto $\mathrm{n}^{0} 4.073$, art. 19 & Recomendável \\
\hline 3.16 & $\begin{array}{l}\text { Processo de validação das guias ou listas de } \\
\text { recolhimento }\end{array}$ & $\begin{array}{l}\text { Resolução CONARQ n } n^{0} \text {, } \\
\text { art. } 2^{\circ}\end{array}$ & Obrigatório \\
\hline 4 & \multicolumn{3}{|c|}{ CLASSIFICAÇÃ̃O E ARRANJO } \\
\hline 4.1 & $\begin{array}{l}\text { Verificação sistemática do uso do plano de } \\
\text { classificação de documentos, tais como a } \\
\text { Resolução no } 14 \text { do CONARQ }\end{array}$ & $\begin{array}{l}\text { Resolução CONARQ no } \\
14 \text {, art. } 1^{\circ}\end{array}$ & Obrigatório \\
\hline 4.2 & $\begin{array}{l}\text { Estabelecimento do processo de organização } \\
\text { dos arquivos correntes com base em } \\
\text { métodos de classificação que consideram } \\
\text { a natureza dos assuntos resultantes das } \\
\text { atividades e funções }\end{array}$ & $\begin{array}{l}\text { Resoluçãa CONARQ n }{ }^{0} 1, \\
\text { art. } 1^{\circ}\end{array}$ & Obrigatório \\
\hline 4.3 & $\begin{array}{l}\text { Classificação de documentos em sua origem } \\
\text { ou entrada na instituição }\end{array}$ & $\begin{array}{l}\text { SCHELLENBERG, 2004, } \\
\text { p. } 95\end{array}$ & Recomendável \\
\hline 4.4 & $\begin{array}{l}\text { Uso da classificação na recuperação dos } \\
\text { documentos }\end{array}$ & $\begin{array}{l}\text { SCHELLENBERG, 2004, } \\
\text { p. } 95\end{array}$ & Recomendável \\
\hline 5 & \multicolumn{3}{|l|}{ DESCRIÇÃO } \\
\hline 5.1 & $\begin{array}{l}\text { Aferição sistemática do uso dos padrões } \\
\text { estabelecidos na Norma Brasileira de } \\
\text { Descrição Arquivística - NOBRADE }\end{array}$ & $\begin{array}{l}\text { Resolução CONARQ no } \\
28 \text {, art. } 1^{\circ}\end{array}$ & Recomendável \\
\hline 5.2 & $\begin{array}{l}\text { Instrumentos de pesquisa no arquivo } \\
\text { permanente }\end{array}$ & BELLOTTO, 2006, p. 174 & Recomendável \\
\hline 6 & \multicolumn{3}{|c|}{ ACESSO } \\
\hline 6.1 & $\begin{array}{l}\text { Processo de franqueamento de acesso } \\
\text { permanente à informação pública }\end{array}$ & $\begin{array}{l}\text { Lei } n^{0} 8.159, \text { de } \\
\text { 08/01/1991, art. } 4^{0} \text { e } 5^{0} ; \\
\text { Lei } n^{0} 12.527 \text {, art. } 1^{\circ}\end{array}$ & Obrigatório \\
\hline
\end{tabular}




\begin{tabular}{|c|c|c|c|}
\hline 6.2 & $\begin{array}{l}\text { Procedimentos formais para consulta e } \\
\text { empréstimo de documentos em arquivo } \\
\text { intermediário }\end{array}$ & & Recomendável \\
\hline 6.3 & $\begin{array}{l}\text { Ações para garantir a observância da } \\
\text { publicidade como preceito geral e do sigilo } \\
\text { como exceção }\end{array}$ & $\begin{array}{l}\text { Lei } \mathrm{n}^{0} 12.527 \text {, art. } 3^{\circ} \text {, } \\
\text { inciso I }\end{array}$ & Obrigatório \\
\hline 6.4 & $\begin{array}{l}\text { Plano de proteção da informação sigilosa e } \\
\text { pessoal }\end{array}$ & $\begin{array}{l}\text { Lei } \mathrm{n}^{0} 12.527 \text {, art. } 6^{0}, \\
\text { inciso III }\end{array}$ & Obrigatório \\
\hline 6.5 & $\begin{array}{l}\text { Regulamentação para obtenção do acesso à } \\
\text { informação }\end{array}$ & $\begin{array}{l}\text { Lei } \mathrm{n}^{0} 12.527, \text { art. } 7^{0} \\
\text { inciso I } \\
\text { Decreto } \mathrm{n}^{0} 7.724 \text {, art. } 2^{\circ}\end{array}$ & Obrigatório \\
\hline 6.6 & Negativas de acesso à informação motivadas & $\begin{array}{l}\text { Lei } n^{0} 12.527, \text { art. } 3^{\circ} \\
\text { inciso VII, alínea b, } \S 4^{\circ}\end{array}$ & Obrigatório \\
\hline 6.7 & $\begin{array}{l}\text { Serviço de Informação ao Cidadão (SIC) em } \\
\text { pleno funcionamento }\end{array}$ & $\begin{array}{l}\text { Lei } \mathrm{n}^{0} 12.527, \text { art. } 9^{\circ}, \\
\text { inciso I }\end{array}$ & Obrigatório \\
\hline 6.9 & $\begin{array}{l}\text { Instalação do SIC em unidade física } \\
\text { identificada, de fácil aceso e aberta ao } \\
\text { público }\end{array}$ & Decreto $\mathrm{n}^{0} 7.724$, art. 10 & Obrigatório \\
\hline 6.10 & $\begin{array}{l}\text { Processo de fornecimento de formulário } \\
\text { eletrônico e físico para solicitação de acesso } \\
\text { à informação }\end{array}$ & $\begin{array}{l}\text { Decreto } \mathrm{n}^{0} 7.724, \text { art. } 11 \\
\S 1^{0}\end{array}$ & Obrigatório \\
\hline 6.11 & $\begin{array}{l}\text { Processo de atendimento dos pedidos de } \\
\text { solicitação dentro do prazo legal (20 dias, } \\
\text { prorrogáveis por mais 10) }\end{array}$ & Decreto $\mathrm{n}^{0} 7.724$, art. 15 & Obrigatório \\
\hline 6.12 & $\begin{array}{l}\text { Processo de classificação da informação } \\
\text { quanto ao grau e prazos de sigilo }\end{array}$ & Lei $\mathrm{n}^{0} 12.527$, art. 23 e 24 & Obrigatório \\
\hline 6.14 & $\begin{array}{l}\text { Garantia de acesso aos documentos de } \\
\text { guarda permanente }\end{array}$ & $\begin{array}{l}\text { Decreto } \mathrm{n}^{0} 4.073, \text { art. } 13, \\
\text { inciso IV }\end{array}$ & Obrigatório \\
\hline 6.15 & \begin{tabular}{|l|} 
Adesão às Recomendações para a \\
Digitalização de Documentos Arquivísticos \\
Permanentes, emanadas pelo CONARQ
\end{tabular} & $\begin{array}{l}\text { Resolução CONARQ no } \\
31 \text {, art. } 1^{\circ}\end{array}$ & Recomendável \\
\hline 7 & \multicolumn{3}{|c|}{ DIFUSÃO/ COMUNICAÇÃO } \\
\hline 7.1 & $\begin{array}{l}\text { Plano de divulgação de informações } \\
\text { de interesse público, independente de } \\
\text { solicitação }\end{array}$ & $\begin{array}{l}\text { Lei } n^{0} 12.527 \text {, art. } 3^{\circ}, \\
\text { inciso II }\end{array}$ & Obrigatório \\
\hline 7.2 & $\begin{array}{l}\text { Utilização de meios de comunicação } \\
\text { viabilizados pela tecnologia da informação }\end{array}$ & $\begin{array}{l}\text { Lei } \mathrm{n}^{0} 12.527, \text { art. } 3^{\circ}, \\
\text { inciso III }\end{array}$ & Obrigatório \\
\hline 7.3 & $\begin{array}{l}\text { Plano de divulgação das informações sobre } \\
\text { classificação de documentos quanto ao sigilo }\end{array}$ & Decreto $\mathrm{n}^{0} 7.724$, art. 45 & Obrigatório \\
\hline 7.4 & $\begin{array}{l}\text { Plano de treinamento para } 0 \\
\text { aperfeiçoamento e reciclagem profissional } \\
\text { na área de arquivo }\end{array}$ & $\begin{array}{l}\text { Decreto } \mathrm{n}^{0} 4.073, \text { art. } 13, \\
\text { inciso XIII }\end{array}$ & Recomendável \\
\hline 7.5 & $\begin{array}{l}\text { Promoção de atividades culturais } \\
\text { relacionadas aos arquivos (eventos e } \\
\text { exposições) }\end{array}$ & BELLOTTO, 2006, p. 228 & Recomendável \\
\hline
\end{tabular}




\begin{tabular}{|c|c|c|c|}
\hline 7.6 & $\begin{array}{l}\text { Planos e programas sistemáticos de difusão } \\
\text { e divulgação }\end{array}$ & BELLOTT0, 2006, p. 228 & Recomendável \\
\hline 7.7 & $\begin{array}{l}\text { Plano de integração com a comunidade } \\
\text { (convênios com escolas, universidades, etc.) }\end{array}$ & BELLOTTO, 2006, p. 229 & Recomendável \\
\hline 7.8 & $\begin{array}{l}\text { Processo de elaboração de publicações com } \\
\text { base nas atividades e acervo arquivísticos }\end{array}$ & BELLOTT0, 2006, р. 229 & Opcional \\
\hline 8 & \multicolumn{3}{|c|}{ PRESERVAÇÃO E CONSERVAÇÃO } \\
\hline 8.1 & $\begin{array}{l}\text { Plano de preservação dos documentos } \\
\text { de valor permanente, como garantia da } \\
\text { integridade física }\end{array}$ & \begin{tabular}{|l|} 
Lei $n^{0} 8.159$, art. 10 \\
Decreto $n^{0} 4.073$, art. 13, \\
inciso IV \\
Lei $n^{0} 12.527$, de \\
$18 / 11 / 2011$, art. $7^{0}$, inciso IV \\
\end{tabular} & Obrigatório \\
\hline 8.2 & $\begin{array}{l}\text { Padrões e procedimentos para a garantia } \\
\text { de autenticidade e acessibilidade dos } \\
\text { documentos }\end{array}$ & \begin{tabular}{|l|} 
Lei $n^{0} 12.527$, art. $7^{0}$ \\
inciso IV \\
Resolução CONARQ $n^{0} 24$ \\
\end{tabular} & Obrigatório \\
\hline 8.3 & $\begin{array}{l}\text { Processo de comunicação sobre atos lesivos } \\
\text { ao patrimônio arquivístico nacional }\end{array}$ & $\begin{array}{l}\text { Decreto } \mathrm{n}^{0} 4.073, \text { art. 13, } \\
\text { inciso } \mathrm{X}\end{array}$ & Obrigatório \\
\hline 8.4 & \begin{tabular}{|l|} 
Processo de punição sobre os responsáveis \\
pela utilização indevida, subtração, destruiçãa, \\
inutilização, desfiguração, alteração ou \\
ocultação de informações e documentos \\
\end{tabular} & $\begin{array}{l}\text { Decreto } \mathrm{n}^{0} 7.724, \text { art. } 65, \\
\text { inciso II }\end{array}$ & Obrigatório \\
\hline 8.5 & $\begin{array}{l}\text { Regulamentação acerca do uso de papéis } \\
\text { reciclados para a produção de documentos } \\
\text { de arquivo }\end{array}$ & $\begin{array}{l}\text { Resolução CONARQ } n^{0} \\
42 \text {, art. } 1^{\circ}\end{array}$ & Recomendável \\
\hline 8.6 & $\begin{array}{l}\text { Plano de guarda física adequada dos } \\
\text { documentos em espaços da própria } \\
\text { instituição }\end{array}$ & $\begin{array}{l}\text { Resolução CONARQ n }{ }^{0} 6, \\
\text { art. } 2^{\circ} .\end{array}$ & Obrigatório \\
\hline 8.7 & $\begin{array}{l}\text { Uso de técnicas de microfilmagem aos } \\
\text { tratamento técnico para preservação dos } \\
\text { documentos }\end{array}$ & \begin{tabular}{|l|} 
Lei $n^{0} 5.433$, de $08 / 05 / 1968$, \\
art. $1^{\circ}$ SCHELLENERG, \\
2004, p. 146 \\
\end{tabular} & Obrigatório \\
\hline 8.8 & $\begin{array}{l}\text { Utilização dos símbolos para microfilmagem } \\
\text { constantes da ISO 9878/1990 }\end{array}$ & $\begin{array}{l}\text { Resolução CONARQ } n^{0} \\
10 \text {, art. } 1^{\circ} \text {. }\end{array}$ & Obrigatório \\
\hline 8.9 & $\begin{array}{l}\text { Localização adequada para a edificação dos } \\
\text { arquivos }\end{array}$ & $\begin{array}{l}\text { Resolução CONARQ no } \\
\text { 13, art. } 1^{0} \text {, inciso II }\end{array}$ & Obrigatório \\
\hline 8.10 & $\begin{array}{l}\text { Espaços diferenciados para a pesquisa, } \\
\text { depósitos e área administrativa }\end{array}$ & $\begin{array}{l}\text { Resolução CONARQ no } \\
13 \text {, art. } 1^{\circ} \text {, inciso II }\end{array}$ & Obrigatório \\
\hline 8.11 & $\begin{array}{l}\text { Edificação sem presença de problemas } \\
\text { estruturais (rachaduras, infiltrações e etc.) }\end{array}$ & $\begin{array}{l}\text { Resolução CONARQ n }{ }^{0} \\
13 \text {, art. } 1^{\circ} \text {, inciso II }\end{array}$ & Obrigatório \\
\hline 8.12 & $\begin{array}{l}\text { Depósitos específicos para documentos } \\
\text { especiais }\end{array}$ & $\begin{array}{l}\text { Resolução CONARQ n }{ }^{0} \\
13 \text {, art. } 1^{\circ} \text {, inciso II }\end{array}$ & Obrigatório \\
\hline 8.13 & $\begin{array}{l}\text { Mobiliário apropriado para o } \\
\text { acondicionamento de documentos de } \\
\text { arquivo (em aço ou madeira tratada contra } \\
\text { insetos) }\end{array}$ & $\begin{array}{l}\text { Resolução CONARQ } n^{0} \\
13 \text {, art. } 1^{\circ} \text {, inciso II }\end{array}$ & Obrigatório \\
\hline
\end{tabular}




\begin{tabular}{|c|c|c|c|}
\hline 8.14 & $\begin{array}{l}\text { Mobiliário apropriado para o } \\
\text { acondicionamento de documentos } \\
\text { de arquivo (respeitando formatos } \\
\text { diferenciados) }\end{array}$ & $\begin{array}{l}\text { Resolução CONARQ } n^{0} \\
13 \text {, art. } 1^{0} \text {, inciso II }\end{array}$ & Obrigatório \\
\hline 8.15 & $\begin{array}{l}\text { Condições ambientais adequadas, de } \\
\text { temperatura e umidade relativa do ar }\end{array}$ & $\begin{array}{l}\text { Resolução CONARQ n } \\
13 \text {, art. } 1^{0} \text {, inciso II }\end{array}$ & Obrigatório \\
\hline 8.16 & Presença de proteção contra a poluição & $\begin{array}{l}\text { Resolução CONARQ n } \\
\text { 13, de 09/02/2001, art. 10, } \\
\text { inciso II }\end{array}$ & Obrigatório \\
\hline 8.17 & Iluminação adequada dos depósitos & $\begin{array}{l}\text { Resolução CONARQ n } \\
13 \text {, art. } 1^{0} \text {, inciso II }\end{array}$ & Obrigatório \\
\hline 8.18 & $\begin{array}{l}\text { Plano de contingência para garantir a } \\
\text { segurança e a integridade do acervo }\end{array}$ & $\begin{array}{l}\text { Resolução CONARQ n } \\
13 \text {, art. } 1^{0} \text {, inciso II }\end{array}$ & Obrigatório \\
\hline 8.19 & Proteção contra roubo e vandalismo & $\begin{array}{l}\text { Resolução CONARQ n } \\
13 \text {, art. } 1^{0} \text {, inciso II }\end{array}$ & Obrigatório \\
\hline
\end{tabular}

Fonte: Elaboração própria

\section{CONSIDERAÇÕES FINAIS}

Após 0 estudo dos conceitos elencados neste trabalho, podemos apontar que a auditoria de gestão de documentos é aquela que avalia os processos de trabalho relacionados com a produção, tramitação, uso, avaliação e destinação de documentos de arquivo, enquanto cumprem seu valor primário; sua conformidade com os preceitos legais e teóricos; aponta divergências e sugere melhorias; e monitora 0 aprimoramento dos processos de trabalho e produtos da referida gestão.

Já a auditoria arquivística é aquela que avalia os procedimentos adotados em todo o ciclo de vida do documento de arquivo, incluindo sua guarda e acesso na fase permanente, em conformidade com diretrizes legais e teóricas da disciplina arquivística; acrescidos de análise crítica, sugestões e monitoramento.

Apesar deste estudo indicar as diferenças básicas entre a auditoria de gestão de documentos e a auditoria arquivística, há que se aprofundar os estudos sobre o tema para a formulação de um modelo conceitual mais específico.

Por meio desta pesquisa foi possível propor requisitos mínimos a serem avaliados por um auditor, como garantia do efetivo tratamento e proteção ao patrimônio público documental. Como afirmado anteriormente, os critérios aqui formulados, tiveram como base a legislação arquivística brasileira e os estudos de três autores da área: Heloísa Liberalli Bellotto, Theodore R. Schellenberg e Antônia Heredia Herrera.

As funções arquivísticas elencadas como classificação dos requisitos propostos neste trabalho poderão ser aprimoradas nas instituições que se submeterem à auditoria arquivística, pois, por 
meio desta atividade, é possível detectar eventuais desvios em sua execução, contribuindo para 0 aprimoramento da gestão dos arquivos nas instituições públicas.

0 produto final deste trabalho pode ser universalizado. A proposta de requisitos de auditoria arquivística pode ser aplicada em qualquer unidade ou instituição arquivística.

Apesar desta pesquisa ter atingido seus objetivos e seu propósito, também gera novos questionamentos que poderão ser respondidos em futuros estudos: como se daria, nos diversos contextos, a aplicação dos requisitos apontados nesta pesquisa? Em âmbito federal, qual seria a instituição com atribuições legais para a realização deste tipo de auditoria?

É possível estabelecer os indicadores de desempenho para cada requisito, ou comparar os resultados deste trabalho com iniciativas vigentes em outros países.

Fica evidente que ainda há um longo caminho a percorrer quanto à produção de conhecimentos científicos relacionados à auditoria arquivística. Cabe à comunidade acadêmica incorporar este objeto de trabalho à sua agenda, compreendendo ser, ele, parte de seu campo de reflexão e de ação.

\section{REFERÊNCIAS}

ALBUQUERQUE, Frederico de Freitas Tenório. A Auditoria operacional e seus desafios: um estudo a partir da experiência do Tribunal de Contas da União. 1. ed. Rio de Janeiro: Ed. Renovar, 2007.

ALMEIDA, Marcelo Cavalcanti. Auditoria: um curso moderno. 5. ed. São Paulo: Ed. Atlas, 1996.

ARAÚJ0, Inaldo da Paixão Santos. Introdução à Auditoria Operacional. 2 ed. Rio de Janeiro: Ed. FGV, 2004.

ARQUIVO NACIONAL (Brasil). Dicionário Brasileiro de Terminologia Arquivística. Rio de Janeiro: Arquivo Nacional. 2005.

ASSOCIAÇÃO BRASILEIRA DE NORMAS TÉCNICAS. NBR ISO 19011:2012: Diretrizes para auditoria de sistemas de gestão. Rio de Janeiro: ABNT, 2012.

BACON, Charles A. Manual de Auditoria Interna. 2. ed. México DF: Ed. UETHA, 1973.

BRASIL. DEC 4.073, de 03/01/2002. Regulamenta a Lei $n^{0} 8.159$, de 8 de janeiro de 1991, que dispõe sobre a política nacional de arquivos públicos e privados. Disponível em: http://www.planalto. gov.br/ccivil_03/decreto/2002/D4073.htm. Acesso em: 07 jan. 2016.

BRASIL. Conselho Federal de Contabilidade. Resolução CFC $\mathbf{n}^{0}$ 1.135, de 21 de novembro de 2008. Disponível em: http://www.cfc.org.br/sisweb/sre/detalhes_sre.aspx?Codigo=2008/001135. Acesso em: 07 jan. 2016. 
BRASIL. [Constituição (1988)]. Constituição da República Federativa do Brasil. Brasília, DF: Senado Federal, 1988.

BRASIL. Ministério da Fazenda. Secretaria Federal de Controle Interno. Manual do sistema de controle interno do Poder Executivo Federal. Anexo à Instrução Normativa $\mathbf{n}^{0}$ 01, de 06 de abril de 2001. Controladoria Geral da União, 2001. Disponível em: http://www.cgu.gov.br/sobre/legislacao/arquivos/ instrucoes-normativas/in-01-06042001.pdf Acesso em: 07 jan. 2016

BRASIL. Tribunal de Contas da União. Secretaria-Geral de Controle Externo. Manual de auditoria operacional / Tribunal de Contas da União. 3.ed. Brasília: TCU, Secretaria de Fiscalização e Avaliação de Programas de Governo (Seprog), 2010. Disponível em: https://portal.tcu.gov.br/biblioteca-digital/manualde-auditoria-operacional-FF8080816364D7980163D01267A73FBD.htm Acesso em: 10 dez. 2015

BRASIL. Tribunal de Contas da União. Secretaria-Geral de Administração. Portaria $\mathbf{n}^{0} \mathbf{2 8 0}$, de 08 de dezembro de 2010. Alterada pela Portaria $\mathbf{n}^{0}$ 168, de 30 de junho de 2011. Altera o Anexo da Portaria-TCU n ${ }^{0}$ 280/2010, que dispõe sobre as Normas de Auditoria do Tribunal de Contas da União (NAT).Brasília. 2011. Disponível em: www.tcu.gov.br/Consultas/Juris/.../20110706/PRT2011-168.doc. Acesso em 10 dez. 2015.

CAMARGO, Ana Maria de Almeida; BELLOTTO, Heloisa Liberalli. Dicionário de Terminologia Arquivística. São Paulo: Associação dos Arquivistas Brasileiros - Núcleo Regional de São Paulo: Secretaria de Estado da Cultura, 1996.

CASTR0, Domingos Poubel. Auditoria, contabilidade e controle interno no Setor Público. 5. ed. São Paulo: Ed. Atlas, 2013.

C00K, John William; WINKLE, Garry M. Auditoria: filosofia e técnica. São Paulo: Ed. Saraiva, 1983. FRANCO, Hilário; MARRA, Ernesto. Auditoria contábil: normas de auditoria, procedimentos e papéis de trabalho. 4. ed. São Paulo: Ed. Atlas, 2001.

GUEDES, William; ARAÚJO JÚNIOR, R. H. 0 fluxo de informações na auditoria pública e a Teoria Matemática da Comunicação. Encontros Bỉbli. v. 19. n. 40. p. 33-50. Mai./Ago. 2014. Disponível em: https://periodicos. ufsc.br/index.php/eb/article/view/1518-2924.2014v19n40p33/27574. Acesso em: 8 jun. 2015.

HEREDIA HERRERA, Antonia. Manual de Archivística Básica: gestión y sistemas. 1. ed. México: Ed. El Errante, 2013.

INTERNATIONAL ORGANIZATION OF STANDARDIZATION. ISO 30300:2011: Information and documentation - Management systems for records - Fundamentals and vocabulary. Geneva. Switzerland: ISO, 2011

MEDAUAR, 0. Controle da Administração Pública. 2. ed. São Paulo: Ed. Revista dos Tribunais, 2012. MÉXICO. Secretaria de Gobiernación. Archivo General de La Nación. Guía para la auditoría archivística. Archivo General de La Nación. 2015.

PETER, Maria da Glória Arrais; MACHADO, Marcus Vinícius Veras. Manual de Auditoria Governamental. 1. ed. São Paulo: Ed. Atlas, 2003.

ROUSSEAU, J; COUTURE, C. Os fundamentos da disciplina arquivística. 1. ed. Lisboa: Ed. Dom Quixote, 1998.

SCHELLENBERG, T. R. Arquivos modernos: princípios e técnicas. 3. ed. Rio de Janeiro: Ed. FGV, 2004. 